\title{
Seroprevalance of Human Parvovirus B19 among Blood Donor Volunteers from Sudanese Blood Bank in Khartoum State 2017
}

Amasi Hassan Omer ${ }^{1}$, Ayat Jamal Al-deen Adam ${ }^{1}$, Fatima Ali Mohamed ${ }^{1}$, Fatima Hashim Hamed ${ }^{1}$, Haram Hussain Edr ${ }^{1}$, Marwa Ahmed Al-sedig ${ }^{1}$, Romisa Hashim Ahmed ${ }^{1}$, Yoonis Ismail Mohammed ${ }^{1}$ and Omnia Mohammed Hamid ${ }^{2^{*}}$

${ }^{1}$ Department of Microbiology, Faculty of Medical Laboratory Sciences, National University Sudan, Khartoum, Sudan

${ }^{2}$ Department of Medical Microbiology, Faculty of Medical Laboratory Sciences, University of Medical Sciences and Technology, Khartoum, Sudan

"Corresponding author: Omnia Mohammed Hamid, Department of Medical Microbiology, Faculty of Medical Laboratory Sciences, University of Medical Sciences and Technology, Khartoum, Sudan, Tel: 249 155772782; E-mail: omnia.m.hamid@gmail.com

Received date: May 22, 2017; Accepted date: July 17, 2017; Published date: July 21, 2017

Copyright: ( 2017 Omer AH, et al. This is an open-access article distributed under the terms of the Creative Commons Attribution License, which permits unrestricted use, distribution, and reproduction in any medium, provided the original author and source are credited.

\begin{abstract}
Background: Human parvovirus B19 is in emerging transfusion transmitted infection, although parvovirus B19 infection is connected with severe complication in some recipients, donor screening is not yet mandatory.
\end{abstract}

Aim: To determine the prevalence of human parvovirus B19-specific-lgG antibody among blood donors attending the central blood bank (STAC) ,Khartoum State, Sudan, and to determine some possible risk factors.

Subjects and Methods: A total of 180 sera samples collected from the participants were screened for human parvovirus B19-specific-IgG antibody using quantitative indirect ELISA technique.

Result: Human parvovirus B19-specific-IgG antibodies were detected in 114/180 (63.3\%). No statistical significance was determined regarding the variables tested in this study and the results of human parvovirus B19specific-lgG antibody detection.

Conclusion: Blood donors might be a source of infection with this virus. These findings form a solid base for further studies on confirming the presence of human parvovirus B19 in donor sera. It should be considered by the ministry of health and blood banks to develop new policies for blood screening.

Keywords: Human parvovirus B19; Human parvovirus B19-specificIgG; Sudanese blood donors; ELISA quantitative titer

Abbreviations: IgG: Immunoglobulin G; IgM: Immunoglobulin M; ELISA: Enzyme-linked immuosorbent assay; Anti-b19: Antibody against parvovirus b19; Hb: Hemoglobin; -ve: Negative; +ve: Positive

\section{Introduction}

A spectrum of blood infectious agents is transmitted through transfusion of infected blood donated by apparently healthy and asymptomatic blood donors [1]. Recent emerging-infectious-disease threats include Parvovirus B19 (B19V), long known to be the causative agent of erythema infectiosum (fifth disease), is not a newly emerging agent. However, it deserves discussion because it may be present in blood and in plasma products, can circulate at extraordinarily high titres, can infect recipients, and, in some cases, can cause severe disease [2]. However, there is always an associated risk of transfusion reactions due to viral transmission via contaminated blood [1], its potentially severe pathological effects have become more apparent in the past decade with the widespread use of (pooled) plasma-derived medicinal products and are the main reason for the uneasy relationship between transfusion medicine specialists and B19V [3]. Parvovirus B19 was discovered by chance in 1975 by australian virologist yvonne cossart in the blood of a healthy blood donor, it gained its name because it was discovered in well B19 of a large series of microtiter plates, belong to the parvoviridae family, non-envloped, icosahedral virus with singlestranded linear DNA genome, parvoviruses are among the smallest known viruses with a virion diameter of $18-26 \mathrm{~nm}$ [3], The icosahedral capsid consist of two structural protien (VP1,VP2). The virus bind to a specific receptor on the surface of host cells ( $\mathrm{P}$ blood group antigen globoside-4 [Gb4] in the case of human B19V).

B19V viraemia occurs 1 week after exposure and usually lasts about 5 days, with virus titers peaking in the first 2 days. IgM antibodies against $\mathrm{B} 19 \mathrm{~V}$ are detected late in the viraemic stage. They appear 10 to 14 days after the infection and can persist for up to 5 months but, in some patients, they can last even longer period [4]. Specific IgG antibodies are detectable about 15 days after infection, remain high for several months and persist long-term [5]. There are different epidemiological patterns of infection; the seroprevalence of B19V IgG varies widely from approximately from $30 \%$ to $40 \%$ in adolescents, $40 \%$ to $60 \%$ in adults, and more than $85 \%$ in elderly populations [5]. Neutralizing IgG antibodies generally appear about 2 weeks after infection and persist lifelong. The aim of this study was to detect antibodies against parvovirus (anti-B19 IgG) in blood donor sera using indirect-ELISA technique and to correlate between the presence of Anti parvovirus b19 IgG and some risk factors (age, gender, blood group and residence). 
Page 2 of 4

\section{Material and Methods}

\section{Study design and population}

This is a descriptive cross-sectional study aimed to screen seroprevalence of parvovirus B19 IgG among blood donors at Central Blood Bank. The serological analysis was done in STAC laboratories. The study was approved by the Research Committee of the Faculty of Medical Laboratory Sciences, National University-Sudan. All blood donors included in this study were consented verbally before collecting the samples.

Data collection techniques: Non-probability sampling technique was used to collect 180 Blood samples from apparently healthy donors and direct interviewing questionnaire were filled to determine the sociodemographic data about the participants.

Inclusion and Exclusion Criteria: The blood donors samples from both gender with age ranged between 18-60 years and who passed the medical and laboratory examination applied before the donation process according to the blood bank policy, were included in this study.

\section{Data analysis and interpretation}

The Blood samples were collected in plain containers, and then sera samples obtained by centrifugation of the blood. The sera kept at $-20^{\circ} \mathrm{C}$ till being analysed by ELISA.

The procedure to run the ELISA test was followed as mentioned by the manufacturer Kits (Euroimmun-EI 2580-9601 G):

Two negative controls, two positive controls and two calibrators were used.

$0.01 \mathrm{ml}$ of each serum sample was applied to separate well of micro plate using automated pipette.

The conjugate was supplemented to each well of micro plate and the plate incubated at $37^{\circ} \mathrm{C}$ for $30 \mathrm{~min}$ for $\mathrm{Ag}$-Abs complex.

After incubation period the micro plate was washed three times in ordered to remove the uncombined Abs.

$0.01 \mathrm{ml}$ of reconstituted substrate was applied to micro plate and incubated at $22^{\circ} \mathrm{C}$ for 15 minutes.

Finally, $0.01 \mathrm{ml}$ of stopped solution was added to each well of micro plate.

Calculation of the results: The optical density (OD) of micro plate was obtained at the $450 \mathrm{~nm}$. The presence or absence of antibody to parvovirus B19 was determined by calculating a ratio of the extinction value of the control or patient sample extinction value of calibrator two. Calculate the ratio according the following formula:

$$
\frac{\text { extinction of the control or patient sample }}{\text { extiction of caliblator } 2}=\text { Ratio }
$$

ELISA calculation: Results evaluated semiquantatively by calculating a ration of the extinction value of the control or patient sample over the extinction value calibrator 3 , the action calculated according to the following formula:

Ratio $=$ extinction of the patient sample/extinction of calibrator 3

Interpreting results as follow: Ratio $<0.8=$ negative titre, Ratio $>$ or $=$ $1.1=$ positive titre and Ratio $>0.8$ or $<1.1=$ border line titre
The questionnaires were analysed to detect the correlation between the carriage status and demographic data. All data include in questionnaire were analysed by SPSS program (statistical package for social sciences) version 21 .

\section{Results}

180 samples were screened for (IgG) antibodies in human serum against parvovirus B19, in blood donors at the central blood bank (STAC), 2017. Most of blood donors participated were males, $99.4 \%$ $(179 / 180)$, (Table 1). The ages of the participants were ranged between 18 and 58 years, and the majority was at age group (29-38) years, as shown in (Table 2). Regarding blood groups, the donors with $\mathrm{O}+\mathrm{ve}$ blood group showed the highest prevalence $44.7 \%$, and the less prevalence among donors with blood group O-ve and A-ve with $1.1 \%$ each was shown in (Table 3) where most of the reside from Khartoum State.

\begin{tabular}{|l|l|l|l|l|}
\hline \multirow{2}{*}{$\begin{array}{l}\text { Donation } \\
\text { gender }\end{array}$} & \multirow{2}{*}{ Number } & \multicolumn{3}{|l|}{ (IgG G) Parvovirus B 19 } \\
\cline { 3 - 5 } & & Positive & Negative & Border line \\
\hline Male & 179 & 114 & 61 & 4 \\
\hline Female & 1 & - & 1 & - \\
\hline Total & $180(100 \%)$ & $114(63.3 \%)$ & $62(34.4 \%)$ & $4(2.2 \%)$ \\
\hline
\end{tabular}

Table 1: The distribution of donation gender which was screened for IgG among suspected blood donor with parvovirus B19. Fischer exact $\mathrm{P}<0.0001$, odds ratio $=179(24.8-1291.65 \%)$.

\begin{tabular}{|l|l|l|l|l|}
\hline \multirow{2}{*}{$\begin{array}{l}\text { Age } \\
\text { group }\end{array}$} & \multicolumn{2}{|l|}{ Number and frequency } & Total \\
\cline { 2 - 5 } & Positive & Negative & Border line & \\
\hline $18-28$ & $48(42.1 \%)$ & $24(38.7 \%)$ & $2(50.0 \%)$ & $74(41.2 \%)$ \\
\hline $29-38$ & $50(43.9 \%)$ & $31(50.0 \%)$ & $2(50.0 \%)$ & $83(46.2 \%)$ \\
\hline $39-48$ & $13(11.4 \%)$ & $7(11.3 \%)$ & - & $20(11.2 \%)$ \\
\hline$>49$ & $3(2.6 \%)$ & - & - & $3(1.4 \%)$ \\
\hline Total & $114(63.3 \%)$ & $62(34.4 \%)$ & $4(2.2 \%)$ & $180(100 \%)$ \\
\hline
\end{tabular}

Table 2: Shows the distribution of different age groups among blood donor with parvovirus B19 IgG G titer in central blood bank Khartoum. Pearson Chi-Square 7.019a, p <0.856. a. 15 cells $(71.4 \%)$ have expected count less than 5 . The minimum expected count is 0.02 .

\begin{tabular}{|l|l|l|l|l|}
\hline \multirow{2}{*}{$\begin{array}{l}\text { Blood } \\
\text { group }\end{array}$} & \multicolumn{2}{|l|}{ Number and frequency } & Total \\
\cline { 2 - 4 } & Positive & Negative & Border line & \multicolumn{1}{|l|}{} \\
\hline O+ve & $51(44.7 \%)$ & $26(41.9)$ & $2(50.0 \%)$ & $79(43.9 \%)$ \\
\hline A+ve & $39(34.2 \%)$ & $20(32.3 \%)$ & $1(25.0 \%)$ & $60(33.3 \%)$ \\
\hline A-ve & $1(0.88 \%)$ & $1(1.6 \%)$ & - & $2(1.1 \%)$ \\
\hline B+ve & $14(12.2 \%)$ & $12(19.3 \%)$ & $1(25.0 \%)$ & $27(15.0 \%)$ \\
\hline AB+ve & $7(6.1 \%)$ & $3(4.8 \%)$ & - & $10(5.6 \%)$ \\
\hline O-ve & $2(1.8 \%)$ & - & - & $2(1.1 \%)$ \\
\hline
\end{tabular}


Page 3 of 4

\begin{tabular}{|l|l|l|l|l|}
\hline Total & $114(63.3 \%)$ & $62(34.4 \%)$ & $4(2.2 \%)$ & $180(100.0 \%)$ \\
\hline
\end{tabular}

Table 3: Distribution of different blood groups among blood donor with parvovirus B19 IgG $\mathrm{G}$ titer in central blood bank Khartoum. Pearson Chi-Square 3.599a, $\mathrm{P}=0.964$. a. 11 cells $(61.1 \%)$ have expected count less than 5 . The minimum expected count is 0.04 .

According to the resident area, the highest prevalence was in Omdurman $37 \%$, followed by $28.9 \%$ in Khartoum (Table 4 ).

\begin{tabular}{|l|l|l|l|l|}
\hline \multirow{2}{*}{ Resident area } & \multicolumn{3}{|l|}{ Number and frequency } & Total \\
\cline { 2 - 5 } & Positive & Negative & Border line & \\
\hline Khartoum State & $98(65 \%)$ & $50(33 \%)$ & $3(2 \%)$ & $151(83.8 \%)$ \\
\hline Outside Khartoum state & $16(55 \%)$ & $12(41 \%)$ & $1(3 \%)$ & $29(16.1 \%)$ \\
\hline Total & $114(63.3 \%)$ & $62(34.4 \%)$ & $4(2.2 \%)$ & $180(100 \%)$ \\
\hline
\end{tabular}

Table 4: Shows the distribution of blood donor with parvovirus B19 IgG titer in central blood bank Khartoum according the resident area. Pearson Chi-Square73.258a, $\mathrm{P}=0.006$. a 0.63 cells $(87.5 \%)$ have expected count less than 5 . The minimum expected count is 0.02 .

\section{Discussion}

Infections with parvovirus B19 are quite common in healthy individuals; the course of infection is usually indolent. B19 infections can result in serious complications in certain high-risk population, but yet donor screening is not compulsory. Because of the epidemic nature of the circulation of $\mathrm{B} 19 \mathrm{~V}$ and its potential as a cause of serious disease, interest in $\mathrm{B} 19 \mathrm{~V}$ seroprevalence has risen throughout the world.

Current attempts, using sensitive screening tests, to improvise blood safety focus entirely on eliminating the risk of transmitting infectious agents. Besides the primary respiratory route of transmission, hospital acquired transmission may occur between family members, from patient to patient and from patient to health care workers [6]. These findings have led to the hypothesis that B19 may also have been transmitted for some years through the administration of blood products to susceptible patients [7].

Of potential concern for blood safety is increasing evidence of long term B19 persistence in the circulation and tissues of immunocompetent individuals.

Seroprevalence of $\mathrm{B} 19 \mathrm{~V}$ in developed countries is $2-10 \%$ in children less than 5 years, $40-60 \%$ in adults over than 20 years, $60 \%$ in blood donors, and $85 \%$ or more in those over 70 years [8]. B19V is recognized as a major contaminant of blood and blood products [9]. In addition, because the virus is resistant to different inactivation methods, most final blood products that contain B19V DNA are potentially infectious [10].

The aim of this study was to measure the seroprevalence of B19Vspecific-IgG antibody in Sudanese blood donors in Khartoum central blood bank.

Of the serum samples of 180 blood donors tested in our study, were positive for B19V-specific-IgG antibody (63.3\%); this prevalence was low when compared with B19V specific-IgG antibody seroprevalence in blood donors in Belgium [10] (74\%), Makkah [11] (76.3\%), and Italy [12] (79.1\%), and it was higher than the B19V specific-IgG antibody seroprevalence reported of blood donors in chaina [13] (16.79\%), Egypt [14] (26\%), Pune [15] (27.96\%), India [16] (39.97\%) and Yemen [14] (46\%).

In our study found, the highest prevalence rate of B19V-specificIgG antibody ( $43.9 \%$ and $42.1 \%$ ) was reported among the age group (29-38) and (18-28) year old respectively, and the lowest prevalence positive rate for $\mathrm{B} 19 \mathrm{~V}$-specific-IgG antibody among age group $>50$ year old was (2.6\%), this result agree with that reported by Alla.O 18 in 2016 Khartoum national laboratory, the highest prevalence rate (66.7\%) belong age group less than 40 years old and less prevalent more than 40 years old $(42.1 \%)$, no significant relation between age and B19V -specific-IgG antibody rate ( $p$ value was $<0.856$ ), this disagree with Abraham M [17] and Ayman K. Johargy [11] which they found that seroprevalence of $\operatorname{IgG}$ antibodies to B19V is known to be age dependent.

In our study there is no significant relation between blood grouping donor and B19V -specific-IgG antibody rate ( $\mathrm{p}$ value was $<0.964$ ) in (STAC) central blood bank Khartoum shows the highest prevalent among donors blood group O+ve blood group was $44.7 \%$ followed by $\mathrm{A}+\mathrm{ve}$ was $33.3 \%$ and the less prevents among donors with blood group $\mathrm{O}$-ve and A-ve with $1.1 \%$ each.

The study showed that the B19V-specific-IgG antibody prevalence high in Khartoum state 65\% (98 out of 151) were less prevalent outside Khartoum state 55\% (16 out of 29), this result agree with result reported by Alla.O [18] in 2016 Khartoum national laboratory (62.2\%) from Khartoum state and (37.8\%) from other Sudan state residence.

Conclusion: The seroprevalence of human parvovirus B19 specificIgG antibodies among blood donor population in central blood bank (STAC), Khartoum State, Sudan, which increased with age 18-38 year old, and poses an adverse transfusion risk especially in high-risk group of patients who have no detectable antibodies to B19. However, more studies on the prevalence and epidemiological pattern of B19V in different area of Sudan are recommended, with larger sample size are needed to validate these results. The high risk-group approach, which includes pregnant women, $\mathrm{Rh}$ isoimmunised pregnancies requiring intrauterine transfusion, patients with congenital or acquired hemolytic anemia and patients with cellular immunodeficiency who have no detectable antibodies to B19, should receive tested blood products. This could serve as an option of choice and by this study to improvise blood safety. Our study was carried on a relatively small group of blood donors due to short research period time, it's recommended that further larger studies are needed on a large numbers of blood donors in different locations and provinces of Sudan to get better overview.

\section{Conflict of interest}

We declare that we have no conflict of interest.

\section{Acknowledgement}

A deep appreciation goes to all persons throughout this project for their kind help in the practical issue. The research project was approved by the research committee of Faculty of Medical Laboratory Sciences, National University Sudan. Khartoum, Sudan as BSc degree requirements to Mrs Omnia M Hamid 
Citation: Omer AH, Al-deen Adam AJ, Mohamed FA, Hamed FH, Edr HH, et al. (2017) Seroprevalance of Human Parvovirus B19 among Blood Donor Volunteers from Sudanese Blood Bank in Khartoum State 2017. J Immuno Biol 2: 127. doi:10.4172/2476-1966.1000127

Page 4 of 4

\section{References}

1. Marano G, Vaglio S, Pupella S, Facco G, Calizzani G, Candura F, et al. (2015) Human Parvovirus B19 and blood product safety: a tale of twenty years of improvements. Blood Transfusion.13: 184-196.

2. Dodd RY (2011) B19: benign or not? Transfusion. 51: 1878-1879.

3. Alter HJ, Stramer SL, Dodd RY (2007) Emerging infectious diseases that threaten the blood supply. Semin Hematol 44: 32-41.

4. Corcoran A, Doyle S (2004) Advances in the biology, diagnosis and hostpathogen interactions of parvovirus B19. J Med Microbiol 53: 459-475.

5. Kuhl U, Pauschinger M, Noutsias M, Seeberg B, Bock T, et al. (2005) High prevalence of viral genomes and multiple viral infections in the myocardium of adults with "idiopathic" left ventricular dysfunction. Circulation. 111: 887-893.

6. Patou G, Pillay D, Myint S, Pattison J (1993) Characterization of a nested polymerase chain reaction assay for detection of parvovirus B19. J Clin Microbiol 31: 540-546.

7. Cohen BJ, Buckley MM (1988) The prevalence of antibody to human parvovirus B19 in England and Wales. J Med Microbiol 25:151-153.

8. Azzi A, Morfini M, Mannucci PM (1999) The transfusion-associated transmission of parvovirus B19. Transfu Med Rev13: 194-204.

9. Koenigbauer UF, Eastlund T, Day JW (2000) Clinical illness due to parvovirus B19 infection after infusion of solvent/detergent-treated pooled plasma. Transfusion 40:1203-1206.

10. Letaief M, Vanham G, Boukef K, Yacoub S, Muylle L, et al. (1997) Higher prevalence of parvovirus B19 in Belgian as compared to Tunisian blood donors: differential implications for prevention of transfusional transmission. Transfusion science. 18: 523-530.
11. Johargy AK (2009) Seroprevalence of Erythrovirus B19 IgG among Saudi blood donors in Makkah, Saudi Arabia. J Family Community Med 16:111-114.

12. Manaresi E, Gallinella G, Morselli Labate AM, Zucchelli P, Zaccarelli D, et al. (2004) Seroprevalence of IgG against conformational and linear capsid antigens of parvovirus B19 in Italian blood donors. Epidemiology and infection. 132: 857-862.

13. Ou SH, Xie JZ, Zhang YL, Ni HY, Song XY (2016) Prevalence of Parvovirus B19 Infection in Chinese Xiamen Area Blood Donors. Zhongguo Shi Yan Xue Ye Xue Za Zhi 24: 1572-1576.

14. Al-Danani D A-DH, Saudi M, Al-Shamahy H (2008) Seroprevalence of parvovirus B19 IgG among blood donors in Aden, Yemen and Alexandria, Egypt. J Chinese Cli Med 3: 173-176.

15. Kishore J, Srivastava M, Choudhary N (2010) Standardization of B19 IgG ELISA to study the seroepidemiology of parvovirus B19 in North Indian voluntary blood donors. Asian J Transfus Sci 4: 86-90.

16. Kumar S, Gupta RM, Sen S, Sarkar RS, Philip J, et al (2013) Seroprevalence of human parvovirus B19 in healthy blood donors. Med J Armed Forces India 69: 268-272.

17. Abraham M, Rudraraju R, Kannangai R, George $\mathrm{K}$, Cherian $\mathrm{T}$, et al. (2002) A pilot study on the seroprevalence of parvovirus B19 infection. Indian J Med Res 115:139-143.

18. Alla.O.A-S. Prevalence of anti-human Parvovirus B19 IgG G among blood donors attending national laboratory for public health blood bank. M.Sc degree research, at Alzaiem Al-Azhari University 2016. 